Article

\title{
Coenzyme Q10 and Oxidative Stress: Inflammation Status in Hepatocellular Carcinoma Patients after Surgery
}

\author{
Hsiao-Tien Liu ${ }^{1,2}$, Shao-Bin Cheng ${ }^{1,2,3}$, Yi-Chia Huang ${ }^{2}$, Yin-Tzu Huang ${ }^{2}$ and \\ Ping-Ting Lin $2,4, *$ \\ 1 Division of General Surgery, Department of Surgery, Taichung Veterans General Hospital, \\ Taichung 40705, Taiwan; langhsky@vghtc.gov.tw (H.-T.L.); sbc@vghtc.gov.tw (S.-B.C.) \\ 2 Department of Nutrition, Chung Shan Medical University, Taichung 40201, Taiwan; \\ ych@csmu.edu.tw (Y.-C.H.); scorpio5220@hotmail.com (Y.-T.H.) \\ 3 School of Medicine, Chung Shan Medical University, Taichung 40201, Taiwan \\ 4 Department of Nutrition, Chung Shan Medical University Hospital, Taichung 40201, Taiwan \\ * Correspondence: apt810@csmu.edu.tw; Tel.: +886-4-2473-0022 (ext. 12187); Fax: +886-4-2324-8175
}

Received: 25 November 2016; Accepted: 28 December 2016; Published: 4 January 2017

\begin{abstract}
Background: Hepatocellular carcinoma (HCC) is the second leading cause of cancer deaths worldwide, and surgical resection is the main treatment for HCC. To date, no published study has examined the status of coenzyme Q10 in patients with HCC after surgery. Thus, the purpose of this study was to investigate the correlations between the level of coenzyme Q10, oxidative stress, and inflammation in patients with HCC after surgery; (2) Methods: 71 primary HCC patients were recruited. Levels of coenzyme Q10, vitamin E, oxidative stress (malondialdehyde), antioxidant enzymes activity (superoxidase dismutase, catalase, and glutathione peroxidase), and inflammatory markers (high sensitivity C-reactive protein; tumor necrosis factor- $\alpha$; and interleukin- 6 ) were measured; (3) Results: Patients with HCC had a significantly lower levels of coenzyme Q10 $(p=0.01)$ and oxidative stress $(p<0.01)$, and significantly higher levels of antioxidant enzymes activities and inflammation after surgery $(p<0.05)$. The level of coenzyme Q10 was significantly positively correlated with antioxidant capacity (vitamin $\mathrm{E}$ and glutathione peroxidase activity) and negatively correlated with inflammation markers after surgery; (4) Conclusion: Hepatocarcinogenesis is associated with oxidative stress, and coenzyme Q10 may be considered an antioxidant therapy for patients with HCC, particularly those with higher inflammation after surgery.
\end{abstract}

Keywords: coenzyme Q10; oxidative stress; inflammation; hepatocellular carcinoma; surgery

\section{Introduction}

The most recent reports from the World Health Organization (WHO, 2014) and the Ministry of Health and Welfare (2014) in Taiwan indicated that hepatocellular carcinoma (HCC) is the second leading cause of cancer deaths [1,2]. Surgical resection is the main treatment for primary HCC [3]. During or after surgical procedures, there is a physiological stress response that involves activation of inflammatory, endocrine, metabolic, and immunological mediators [4]. Oxidative stress, which is defined as a disturbance in the balance between the productions of reactive oxygen species (ROS) and antioxidant defenses [5]. The increase in the oxidative stress during or after surgery may be associated with increasing complications such as myocardial injury, sepsis, pulmonary edema, kidney and liver failure, and increased mortality $[4,6,7]$. As a result, oxidative stress and inflammation status is related to the prognosis of the disease after surgery in HCC patients.

Hepatocytic proteins, lipids, and DNA may affect ROS that are primarily produced in the mitochondria [8]. Coenzyme Q10 (also called ubiquinone) is a lipid-soluble benzoquinone that 
has 10 isoprenyl units in its side chain and is a key component of the mitochondrial respiratory chain for adenosine triphosphate synthesis $[9,10]$. Studies has been indicated that coenzyme Q10 is an intracellular antioxidant can protects membrane phospholipids, mitochondrial membrane protein, and low density lipoprotein-cholesterol (LDL-C) from free radical-induced oxidative damage [11,12]. In vitro or in vivo studies have demonstrated that coenzyme Q10 not only plays an antioxidant, but also has anti-inflammation effects $[13,14]$ by modulating the expression of cyclooxygenase- 2 and nuclear factor- $\mathrm{kB}(\mathrm{NF}-\mathrm{kB})$ in the liver tissue of rats with HCC $[15,16]$. However, to date, no published study has examined the status of coenzyme Q10 in patients with HCC and the correlation between oxidative stress and inflammation with coenzyme Q10 after surgery. Thus, the purpose of this clinical study was to investigate the levels of coenzyme Q10, oxidative stress, and inflammation status in patients with HCC before and after surgery.

\section{Materials and Methods}

\subsection{Participants}

A total of 71 patients were diagnosed with primary HCC (International Classification of Diseases 9, code 155.0) were recruited from the Division of General Surgery of Taichung Veterans General Hospital, which is a teaching hospital in Taiwan. We excluded patients who were younger than 20 years of age or older than 80 years of age, as well as during pregnant or lactating women, patients undergoing chemotherapy or hormone therapy, and those with a history or current diagnosis of cardiovascular or renal disease. Informed consent was obtained from each subject. This study was approved by the Institutional Review Board of Taichung Veterans General Hospital, Taiwan (CF13197) and registered at Clinical Trials.gov Identifier: NCT01964001.

The following data were recorded for all subjects before surgery: age, body weight, height, waist and hip circumference, smoking and drinking habits, exercise frequency, body mass index (BMI), and the waist/hip ratio were calculated. Dietary intake was assessed by dietitians, and $24 \mathrm{~h}$ diet recall was used after one month of the surgery. The dietary records were analyzed using the Nutritionist Professional software package (E-Kitchen Business Corp., Taichung, Taiwan) and the nutrient database was based on the Taiwan food composition table (Food and Drug Administration, Ministry of Health and Welfare, Taipei, Taiwan).

\subsection{Blood Collection and Biochemical Measurement}

Fasting blood specimens were collected in vacutainer tubes without anticoagulant (Becton Dickinson, Rutherford, NJ, USA) before and month after surgery. Serum and plasma were prepared after centrifugation $\left(3000 \mathrm{rpm}, 4{ }^{\circ} \mathrm{C}, 15 \mathrm{~min}\right.$ ) and were then stored at $-80{ }^{\circ} \mathrm{C}$ until analysis. Hematological entities, such as blood urea nitrogen, creatinine, glutamic oxaloacetic transaminase, glutamic pyruvate transaminase (GPT), and lipid profiles were measured using an automated biochemical analyzer (Hitachi-7180E, Tokyo, Japan). The level of high sensitivity C-reactive protein (hs-CRP) was quantified by particle-enhanced immunonephelometry with an image analyzer (Dade Behring, Chicago, IL, USA). Plasma tumor necrosis factor- $\alpha$ (TNF- $\alpha$ ) (R \& D Systems Inc., Minneapolis, MN, USA) and interleukin-6 (IL-6) (eBioscience, San Diego, CA, USA) levels were measured using an enzyme-linked immunosorbent assay (ELISA) with commercially available kits, according to the manufacturer's instructions.

Plasma coenzyme Q10 and vitamin E levels were measured using high-performance liquid chromatography (HPLC) and were detected with a UV detector at $275 \mathrm{~nm}$ and $292 \mathrm{~nm}$, respectively $[17,18]$. Plasma malondialdehyde (MDA) was determined using the TBARs (thiobarbituric acid reactive substances) method, as described by Botsoglou [19]. The red blood cell (RBC) samples were washed with normal saline after removing the plasma. Then, the RBC samples were diluted with a $25 x$ sodium phosphate buffer for superoxide dismutase (SOD) and glutathione peroxidase (GPx) measurements, with a 250x sodium phosphate buffer for the catalase (CAT) measurement. 
The antioxidant enzymes activities (CAT, SOD, and GPx) were determined in the fresh samples, and the methods used to measure these activities have been previously described [20-22]. The protein content of the plasma and RBC was determined based on the biuret reaction of the bicinchoninic acid (BCA) kit (Thermo, Rockford, IL, USA). The values of the antioxidant enzymes activities were expressed as unit/mg of protein. All analyses were performed in duplicate.

\subsection{Statistical Analysis}

The data were expressed as means and standard deviations (SD), as well as medians. A Kolmogorov-Smirnov test was used to examine the normal distribution of variables. A paired $t$-test was used to compare mean values for continuous variables before and after surgery. Pearson product moment correlation was used to examine the correlations between the levels of antioxidant capacity, oxidative stress, and inflammatory markers in HCC patients and the change of coenzyme Q10, antioxidant capacity, oxidative stress, and inflammation in HCC patients after surgery. Simple linear regression was used to examine the correlations between the levels of coenzyme Q10 and vitamin E, and antioxidant enzyme activity (GPx) in HCC patients. Statistical significance was set at $p<0.05$. All statistical analyses were performed using SigmaPlot software (version 12.0, Systat, San Jose, CA, USA).

\section{Results}

\subsection{Participant Characteristics}

The characteristics and dietary intake of the subjects are shown in Table 1 . In total, $70 \%$ of the subjects were males, and the mean age of the subjects were $59 \pm 11$ years old. The frequencies of smoking, drinking, and exercise habits were $17 \%, 9 \%$, and $44 \%$, respectively. Additionally, $39 \%$ of the subjects had been infected with hepatitis B, $17 \%$ of the subjects had been infected with hepatitis $C$, and $14 \%$ of the subjects were cirrhosis. More than half of the subjects (56\%) had HCC recurrence. With regard to the hematological data, the subjects had significantly higher levels of blood urea nitrogen (BUN), creatinine, and high density lipoprotein-cholesterol (HDL-C) and lower levels of glutamic oxalocetic transaminase (GOT) and total cholesterol to high density lipoprotein-cholesterol ratios (TC-to-HDL-C ratios) $(p<0.01)$ after surgery. With regard to dietary intake, subjects had a significantly higher protein intake of total calories $(p=0.04)$ and lower fat intake $(p=0.07)$ after surgery.

Table 1. Characteristics and dietary intake of subjects ${ }^{1}$.

\begin{tabular}{cc}
\hline Subjects Characteristics & \\
\hline males $(n, \%)$ & $50(70 \%)$ \\
age (years) & $59.2 \pm 11.3(59.0)$ \\
SBP (mmHg) & $125.3 \pm 11.3(123.0)$ \\
DBP (mmHg) & $76.9 \pm 12.3(76.5)$ \\
waist circumference (cm) & $88.9 \pm 8.6(90.0)$ \\
waist hip ratio & $0.9 \pm 0.1(0.9)$ \\
BMI $\left(\mathrm{kg} / \mathrm{m}^{2}\right)$ & $24.4 \pm 5.8(24.0)$ \\
current smokers ${ }^{2}(n, \%)$ & $12(17 \%)$ \\
drink alcohol $^{3}(n, \%)$ & $6(9 \%)$ \\
exercise ${ }^{4}(n, \%)$ & $31(44 \%)$ \\
Hepatitis B, $n(\%)$ & $28(39 \%)$ \\
Hepatitis C, $n(\%)$ & $12(17 \%)$ \\
Cirrhosis, $n(\%)$ & $10(14 \%)$ \\
Recurrence, $n(\%)$ & $40(56 \%)$ \\
\hline
\end{tabular}


Table 1. Cont.

\begin{tabular}{cccc}
\hline Subjects Characteristics & & & \\
\hline Hematology & Before Surgery & After Surgery & $p$ Values \\
\hline BUN (mmol/L) & $9.9 \pm 3.6(9.3)$ & $11.6 \pm 4.8(10.7)$ & $<0.01$ \\
creatinine $(\mu \mathrm{mol} / \mathrm{L})$ & $70.7 \pm 17.7(70.7)$ & $79.6 \pm 26.5(70.7)$ & $<0.01$ \\
GOT $(\mathrm{IU} / \mathrm{L})$ & $63.2 \pm 61.4(38.0)$ & $40.1 \pm 36.3(40.0)$ & $<0.01$ \\
GPT $(\mathrm{IU} / \mathrm{L})$ & $60.4 \pm 57.4(38.5)$ & $54.3 \pm 47.8(40.0)$ & 0.79 \\
TC $(\mathrm{mmol} / \mathrm{L})$ & $4.3 \pm 1.0(4.2)$ & $4.3 \pm 0.8(4.2)$ & 0.20 \\
TG (mmol/L) & $1.1 \pm 0.5(1.0)$ & $1.1 \pm 0.4(1.0)$ & 0.64 \\
LDL-C (mmol/L) & $2.8 \pm 0.9(2.8)$ & $2.7 \pm 0.8(2.6)$ & 0.97 \\
HDL-C (mmol/L) & $1.2 \pm 0.3(1.1)$ & $1.3 \pm 0.3(1.2)$ & $<0.01$ \\
TC/HDL-C & $3.8 \pm 1.2(3.5)$ & $3.5 \pm 1.0(3.4)$ & $<0.01$ \\
\hline Dietary Intake & & & \\
energy (kcal/day) & $1952.0 \pm 546.8(1819.9)$ & $1796.2 \pm 405.9(1793.3)$ & 0.21 \\
protein $(\mathrm{g} /$ day) & $67.6 \pm 23.3(64.9)$ & $68.7 \pm 20.6(72.6)$ & 0.28 \\
$\%$ of total calories & $13.7 \pm 3.2(13.0)$ & $15.2 \pm 3.7(14.9)$ & 0.04 \\
fat (g/day) & $66.7 \pm 32.6(54.8)$ & $55.4 \pm 22.0(53.1)$ & 0.07 \\
\% of total calories & $30.3 \pm 10.1(29.0)$ & $26.8 \pm 7.7(26.4)$ & 0.10 \\
carbohydrate (g/day) & $274.0 \pm 92.9(253.0)$ & $264.3 \pm 66.9(258.9)$ & 0.52 \\
$\%$ of total calories & $55.9 \pm 10.8(57.0)$ & $58.3 \pm 7.8(59.4)$ & 0.26 \\
dietary fiber (g/day) & $14.5 \pm 7.3(13.0)$ & $14.7 \pm 7.4(12.7)$ & 0.47 \\
cholesterol (mg/day) & $244.1 \pm 178.0(186.6)$ & $233.3 \pm 147.3(225.7)$ & 0.63 \\
vitamin E (mg $\alpha$-TE/day) & $271.8 \pm 489.1(13.0)$ & $563.8 \pm 888.1(18.0)$ & 0.28 \\
\hline
\end{tabular}

1 mean \pm SD (medians); ${ }^{2}$ current smokers: individuals who current smoke one or more cigarettes per day; ${ }^{3}$ drink alcohol: individuals who regularly drink one or more drink per day; ${ }^{4}$ exercise: individuals who exercise at least three times every week. BMI: body mass index; BUN: blood urea nitrogen; DBP: diastolic blood pressure; GOT: glutamic oxaloacetic transaminase; GPT: glutamic pyruvate transaminase; HDL-C: high-density lipoprotein-cholesterol; LDL-C: low density lipoprotein-cholesterol; SBP: systolic blood pressure; TC: total cholesterol; TG: triglyceride.

\subsection{Levels of Coenzyme Q10, Oxidative Stress, and Inflammation}

The levels of coenzyme Q10, vitamin E, oxidative stress and inflammatory markers after surgery are shown in Table 2. After surgery, the subjects had a significantly lower levels of coenzyme Q10 $(p=0.01)$ and MDA $(p<0.01)$, and significantly higher levels of vitamin $\mathrm{E}(p<0.01)$ and antioxidant enzymes activities (SOD, $p<0.01$; CAT, $p<0.01$; GPx, $p=0.04$ ). With regard to inflammatory markers, the subjects had significantly higher levels of hs-CRP $(p=0.04)$, TNF- $\alpha(p<0.01)$ and IL-6 $(p<0.01)$ after surgery.

Table 2. Levels of coenzyme Q10, oxidative stress, and inflammation ${ }^{1}$.

\begin{tabular}{cccc}
\hline & Before Surgery & After Surgery & $p$ Values \\
\hline Coenzyme Q10 $(\mu \mathrm{M})$ & $0.34 \pm 0.11(0.32)$ & $0.33 \pm 0.11(0.28)$ & 0.01 \\
Vitamin E $\mu \mathrm{M})$ & $10.4 \pm 2.9(11.8)$ & $11.8 \pm 2.6(10.2)$ & $<0.01$ \\
\hline Oxidative Stress & & & \\
\hline MDA $(\mu \mathrm{M})$ & $1.68 \pm 0.40(1.60)$ & $1.43 \pm 0.43(1.36)$ & $<0.01$ \\
\hline Antioxidant Enzymes Activity & & & \\
\hline SOD (U/mg protein) & $13.2 \pm 6.4(12.4)$ & $15.3 \pm 6.8(13.5)$ & $<0.01$ \\
CAT (U/mg protein) & $13.2 \pm 5.7(11.4)$ & $15.3 \pm 7.2(12.5)$ & $<0.01$ \\
GPx (U/mg protein) & $15.7 \pm 4.9(16.3)$ & $16.4 \pm 4.6(16.8)$ & 0.04 \\
\hline Inflammatory Markers & & & \\
\hline hs-CRP $(\mathrm{mg} / \mathrm{L})$ & $4.6 \pm 8.5(1.3)$ & $4.8 \pm 5.0(2.5)$ & 0.04 \\
TNF- $\alpha(\mathrm{pg} / \mathrm{mL})$ & $0.4 \pm 0.7(0.1)$ & $0.9 \pm 1.0(0.8)$ & $<0.01$ \\
IL-6 $(\mathrm{pg} / \mathrm{mL})$ & $2.3 \pm 1.9(1.6)$ & $3.6 \pm 2.8(2.5)$ & $<0.01$ \\
\hline
\end{tabular}

${ }^{1}$ mean \pm SD (medians). CAT: Catalase activity; MDA: Malondialdehyde; GPx: glutathione peroxidase; HCC: hepatocellular carcinoma; hs-CRP: high sensitivity C-reactive protein; IL-6: interleukin-6; SOD: superoxide dismutase; TNF- $\alpha$ : tumor necrosis factor- $\alpha$. 


\subsection{Correlations between Coenzyme Q10, Oxidative Stress, and Inflammation}

The correlations between coenzyme Q10, oxidative stress, and inflammation in HCC patients are shown in Table 3. There was a significantly negative correlation between oxidative stress (MDA) and antioxidant enzymes activities (SOD, $p=0.05$; CAT, $p<0.05$, and GPx, $p=0.04$ ) (Table 3). With regard to the correlation between antioxidant capacity and inflammation, CAT activity shown to be significantly negatively correlated with the level of hs-CRP $(p=0.02)$, and GPx activity was significantly negatively correlated with the levels of TNF- $\alpha(p=0.02)$ and IL-6 $(p<0.01)$.

Table 3. Correlations ${ }^{1}$ between coenzyme Q10, oxidative stress, and inflammation in HCC patients.

\begin{tabular}{lcccc}
\hline & Oxidative Stress & \multicolumn{3}{c}{ Inflammatory Markers } \\
\cline { 2 - 5 } & MDA $(\mu \mathrm{M})$ & hs-CRP $(\mathbf{m g} / \mathbf{d L})$ & TNF- $\alpha(\mathbf{p g} / \mathbf{m L})$ & IL-6 (pg/mL) \\
\hline Coenzyme Q10 $(\mu \mathrm{M})$ & 0.13 & 0.14 & -0.06 & 0.02 \\
vitamin E $(\mu \mathrm{M})$ & 0.07 & 0.09 & -0.04 & 0.24 \\
SOD $(\mathrm{U} /$ mg protein) & $-0.10^{\dagger}$ & 0.00 & 0.18 & 0.13 \\
CAT $(\mathrm{U} /$ mg protein) & $-0.10^{*}$ & $-0.15^{*}$ & 0.51 & 0.14 \\
GPx $(\mathrm{U} /$ mg protein) & $-0.11^{*}$ & -0.08 & $-0.17^{*}$ & $-0.19^{*}$ \\
\hline
\end{tabular}

${ }^{1}$ correlation coefficient $(r) .{ }^{*} p<0.05 ;{ }^{\dagger} p=0.05$. CAT: Catalase activity; MDA: Malondialdehyde; GPx: glutathione peroxidase; HCC: hepatocellular carcinoma; hs-CRP: high sensitivity C-reactive protein; IL-6: interleukin-6; SOD: superoxide dismutase; TNF- $\alpha$ : tumor necrosis factor- $\alpha$.

Furthermore, we assessed the correlations between the changes in coenzyme Q10, oxidative stress, and inflammation in HCC patients, and these results are shown in Table 4. There was a significantly negative correlation between changes in the levels of coenzyme Q10 and inflammation markers (hs-CRP, $p=0.02$; IL-6, $p=0.05$ ) after surgery. In addition, changes in GPx activity were significantly negatively correlated with changes in oxidative stress (MDA, $p=0.06$ ) and inflammation markers (hs-CRP, $p<0.05$; IL-6, $p=0.04$ ), and changes in SOD activity was significantly negatively correlated with changes in hs-CRP $(p=0.04)$ after surgery.

Table 4. Correlations ${ }^{1}$ between changes in coenzyme Q10, oxidative stress, and inflammation.

\begin{tabular}{lcccc}
\hline & Changes of Oxidative Stress & \multicolumn{2}{c}{ Changes of Inflammatory Markers } \\
\cline { 2 - 5 } & MDA $(\mu \mathrm{M})$ & hs-CRP $(\mathbf{m g} / \mathbf{d L})$ & TNF- $\alpha$ (pg/mL) & IL-6 (pg/mL) \\
\hline Coenzyme Q10 $(\mu \mathrm{M})$ & -0.11 & $-0.23^{*}$ & 0.18 & $-0.16^{*}$ \\
vitamin E $(\mu \mathrm{M})$ & 0.01 & 0.09 & -0.13 & 0.08 \\
SOD $(\mathrm{U} / \mathrm{mg}$ protein) & -0.04 & $-0.16^{*}$ & 0.04 & -0.07 \\
CAT $(\mathrm{U} / \mathrm{mg}$ protein) & -0.09 & -0.03 & 0.24 & 0.01 \\
GPx $(\mathrm{U} / \mathrm{mg}$ protein) & $-0.18^{+}$ & $-0.26^{*}$ & -0.10 & -0.20 \\
\hline
\end{tabular}

${ }^{1}$ correlation coefficient $(r) .{ }^{*} p<0.05 ;{ }^{\dagger} p=0.06$. CAT: Catalase activity; MDA: Malondialdehyde; GPx: glutathione peroxidase; HCC: hepatocellular carcinoma; hs-CRP: high sensitivity C-reactive protein; IL-6: interleukin-6; SOD: superoxide dismutase; TNF- $\alpha$ : tumor necrosis factor- $\alpha$.

\subsection{Correlations between Coenzyme Q10 and Antioxidant Capacity}

The correlations between coenzyme Q10 and antioxidant capacity is shown in Figure 1. The level of coenzyme Q10 was significantly positive correlated with vitamin $\mathrm{E}(\beta=9.85, p<0.01)$ and GPx activity $(\beta=6.43, p=0.04)$ in HCC patients. 
(A)

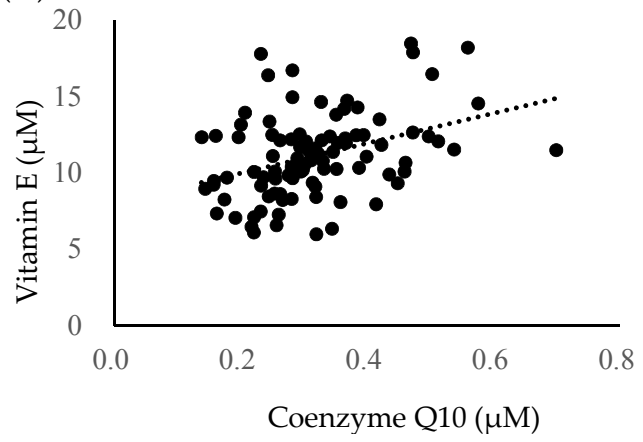

(B)

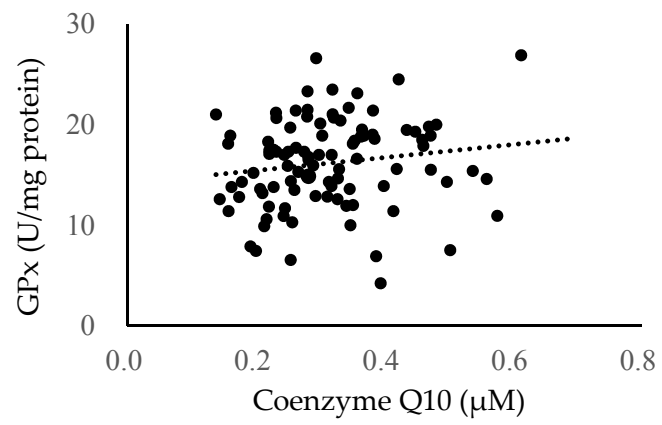

Figure 1. Correlations between the levels of coenzyme $\mathrm{Q} 10$ and vitamin $\mathrm{E}$, and glutathione peroxidase activity (GPx) in HCC patients. (A) Correlation between the levels of coenzyme Q10 and vitamin E $(\beta=9.85, p<0.01)$; (B) Correlation between the levels of coenzyme $\mathrm{Q} 10$ and glutathione peroxidase (GPx, $\beta=6.43, p=0.04)$.

\section{Discussion}

This study is the first clinical study to investigate the coenzyme Q10 status in patients with HCC before and after surgery. The reference values of the level of coenzyme Q10 were suggested to be between 0.5 to $1.7 \mu \mathrm{M}$ [23]. It is worth noting that the level of coenzyme Q10 was lower in patients with HCC before surgery (Table 2), and the level of coenzyme Q10 was further reduced significantly after surgery (Table 2, $0.34 \pm 0.11 \mu \mathrm{M}$ reduced to $0.30 \pm 0.11 \mu \mathrm{M}, p<0.01$ ). Coenzyme Q10 is a crucial cellular antioxidant $[9,10]$, and our previous studies have demonstrated that coenzyme Q10 can significantly reduce oxidative stress and inflammation status via its antioxidant capacity [24-26]. In the present study, we found that the level of coenzyme Q10 was significantly correlated with vitamin E and antioxidant enzyme (GPx) activity in HCC patients (Figure 1). Patients with HCC suffer from a higher level of oxidative stress and inflammation [27], and a deficiency in coenzyme Q10 was found in HCC patients, we suggest that the administration of coenzyme Q10 supplements in patients with HCC during the surgery may be beneficial.

Surgical resection is the most efficient treatment of patients with HCC [3]. Over the past 10 years, surgical treatment has been considered safe, with an acceptable overall mortality rate $(<5 \%)$, and resulted in good long-term survival $(>50 \%)$ in HCC patients [28-30]. However, surgery may elicit the activation of systemic inflammatory, endocrine/metabolic, and immunological systems, which is referred to as the surgical stress response [4]. In the present study, it is interesting to note that, after one month of the surgery, patients with HCC exhibited significantly lower oxidative stress and higher antioxidant enzymes activities (Table 2). The level of oxidative stress (MDA) was significantly reduced by $15 \%$, and the antioxidant activities of SOD, CAT, and GPx were significantly increased by $8.6 \%, 9.6 \%$, and $3.1 \%$, respectively. Although surgery improved the antioxidant capacity in HCC patients, compared with the administration of antioxidants, these increases were not high [24-26,31]. Our previous clinical intervention study have observed that the administration of coenzyme Q10 at a dose of $300 \mathrm{mg} /$ day in patients with HCC could significantly increase the antioxidant enzymes activities of SOD by $67.3 \%$, CAT by $42.6 \%$, and GPx by $26.5 \%$ and reduce oxidative stress by $17.3 \%$ after 12 weeks of supplementation [31]. In the present study, we found a non-statistically negative correlation between the changes in coenzyme Q10 and the changes in oxidative stress (MDA) after surgery (Table 4) and the level of coenzyme Q10 was significantly positive correlated with vitamin $\mathrm{E}$ and antioxidant enzyme (GPx) activity in HCC patients (Figure 1). Additionally, the latest clinical study conducted by Cannistrà et al. [32] demonstrated that the rates for the morbidity, muscle weakness, and pleural effusion were significantly lower in elderly patients with HCC during surgical resection after coenzyme Q10 supplementation. Since hepatocarcinogenesis is associated with severe oxidative 
stress [33], antioxidants, such as coenzyme Q10, could be considered a complementary treatment strategy for patients with HCC after surgery.

With regard to inflammation status, surgery may elicit systemic immunological and inflammatory responses, including the activation of polymorphonuclear leucocytes, macrophages, monocytes, platelets, and mast cells, as well as the hyper-production of cytokines (e.g., IL-6 and TNF- $\alpha$ ) [4]. Similar findings were observed in the present study, patients with HCC had a significantly higher inflammation status after surgery (Table 2). It is not surprising that a higher inflammation status in these patients due to the response to the surgery. However, in the present study, we found that changes in coenzyme Q10 were significantly negatively correlated with inflammation after surgery (Table 4). Most patients with HCC occur in cirrhotic livers and are associated with oxidative stress [30]. It is already known that inflammation is associated with NF-kB activation [34], and NF-kB can be activated by ROS, subsequently resulting in the upregulation of the expression of pro-inflammatory cytokines. Oxidative stress can also induce the production of a variety of cytokines in Kupffer cells, thus increasing inflammation and the apoptosis of hepatic cells [35]. As inflammation is correlated with oxidative stress, using antioxidants to inhibit the inflammatory-activating cascade could be considered. We suggest that administering antioxidants, such as coenzyme Q10, in HCC patients, particularly in those with a lower coenzyme Q10 status after surgery, is worth attempting.

\section{Conclusions}

In this clinical study, we clarified that patients with HCC exhibited lower levels of coenzyme Q10 and oxidative stress after surgery, and the level of coenzyme Q10 was associated with antioxidant capacity and inflammation. As hepatocarcinogenesis is chronic inflammation associated with severe oxidative stress, antioxidants, such as coenzyme Q10, could be considered a complementary treatment strategy for patients with HCC, particularly those with higher inflammation after surgery.

Acknowledgments: This study was supported by a grant from the Taichung Veterans General Hospital (TCVGH-1034601A and TCVGH-1044601A), Taiwan. We would like to express our sincere appreciation to the subjects for their participation. We thank the nurses at Taichung Veterans General Hospital and the technical advisor at the Taipei Institute of Pathology for providing expert assistance in blood sample collection and data analysis.

Author Contributions: H.T.L., S.B.J. and Y.C.H. performed the study and the data analyses. Y.T.H. helped to perform the study and analyze samples. P.T.L. conceived the study, participated in its design, and coordinated the study. H.T.L. and P.T.L. drafted the manuscript. All authors read and approved the final manuscript.

Conflicts of Interest: The authors declare no conflict of interest.

\section{Abbreviations}

The following abbreviations are used in this manuscript:

$\begin{array}{ll}\text { BMI } & \text { body mass index } \\ \text { BUN } & \text { blood urea nitrogen } \\ \text { CAT } & \text { catalase } \\ \text { DBP } & \text { diastolic blood pressure } \\ \text { GPx } & \text { glutathione peroxidase } \\ \text { GOT } & \text { glutamic oxaloacetic transaminase } \\ \text { GPT } & \text { glutamic pyruvate transaminase } \\ \text { HDL-C } & \text { high-density lipoprotein-cholesterol } \\ \text { hs-CRP } & \text { high sensitivity C-reactive protein } \\ \text { IL-6 } & \text { interleukin-6 } \\ \text { LDL-C } & \text { low density lipoprotein-cholesterol } \\ \text { MDA } & \text { malondialdehyde } \\ \text { SBP } & \text { systolic blood pressure } \\ \text { SOD } & \text { superoxide dismutase } \\ \text { TC } & \text { total cholesterol } \\ \text { TG } & \text { triglyceride }\end{array}$




\section{References}

1. Stewart, B.W.; Wild, C.P. World Cancer Report 2014; IARC Nonserial Publication: Lyon, France, 2014. Available online: http://publications.iarc.fr/Non-Series-Publications/World-Cancer-Reports/WorldCancer-Report-2014 (accessed on 4 October 2016).

2. El-Serag, H.B. Hepatocellular carcinoma. N. Engl. J. Med. 2011, 365, 1118-1127. [CrossRef] [PubMed]

3. Helling, T.S. Liver failure following partial hepatectomy. HPB 2006, 8, 165-174. [CrossRef] [PubMed]

4. Kücükakin, B.; Gögenur, I.; Reiter, R.J.; Rosenberg, J. Oxidative stress in relation to surgery: Is there a role for the antioxidant melatonin? J. Surg. Res. 2009, 152, 338-347. [CrossRef] [PubMed]

5. Betteridge, D.J. What is oxidative stress? Metab. Clin. Med. 2000, 49, 3-8. [CrossRef]

6. Cornu-Labat, G.; Serra, M.; Smith, A.; McGregor, W.E.; Kasirajan, K.; Hirko, M.K.; Turner, J.J.; Rubin, J.R. Systemic consequences of oxidative stress following aortic surgery correlate with the degree of antioxidant defenses. Ann. Vasc. Surg. 2000, 14, 31-36. [CrossRef] [PubMed]

7. Hafez, H.M.; Berwanger, C.S.; McColl, A.; Richmond, W.; Wolfe, J.H.; Mansfield, A.O.; Stansby, G. Myocardial injury in major aortic surgery. J. Vasc. Surg. 2000, 31, 742-750. [CrossRef] [PubMed]

8. Cichoż-Lach, H.; Michalak, A. Oxidative stress as a crucial factor in liver diseases. World J. Gastroenterol. 2014, 20, 8082-8091. [CrossRef] [PubMed]

9. Ernster, L.; Dallner, G. Biochemical, physiological and medical aspects of ubiquinone function. Biochim. Biophys. Acta Mol. Basic Dis. 1995, 1271, 195-204. [CrossRef]

10. Bhagavan, H.N.; Chopra, R.K. Coenzyme Q10: Absorption, tissue uptake, metabolism and pharmacokinetics. Free Radic. Res. 2006, 40, 445-453. [CrossRef] [PubMed]

11. Alleva, R.; Tomasetti, M.; Battino, M.; Curatola, G.; Littarru, G.P.; Folkers, K. The roles of coenzyme Q10 and vitamin $\mathrm{E}$ on the peroxidation of human low density lipoprotein subfractions. Proc. Natl. Acad. Sci. USA 1995, 92, 9388-9391. [CrossRef] [PubMed]

12. Flowers, N.; Hartley, L.; Todkill, D.; Stranges, S.; Rees, K. Co-enzyme Q10 supplementation for the primary prevention of cardiovascular disease. Cochrane Database Syst. Rev. 2014, 12, CD010405.

13. Rauchová, H.; Battino, M.; Fato, R.; Lenaz, G.; Drahota, Z. Coenzyme Q-pool function in glycerol-3-phosphate oxidation in hamster brown adipose tissue mitochondria. J. Bioenerg. Biomembr. 1992, 24, 235-241. [CrossRef] [PubMed]

14. Yoneda, T.; Tomofuji, T.; Kawabata, Y.; Ekuni, D.; Azuma, T.; Kataoka, K.; Kunitomo, M.; Morita, M. Application of coenzyme Q10 for accelerating soft tissue wound healing after tooth extraction in rats. Nutrients 2014, 6, 5756-5769. [CrossRef] [PubMed]

15. Fouad, A.A.; Al-Mulhim, A.S.; Jresat, I. Therapeutic effect of coenzyme Q10 against experimentally-induced hepatocellular carcinoma in rats. Environ. Toxicol. Pharmacol. 2013, 35, 100-108. [CrossRef] [PubMed]

16. Kim, J.M.; Park, E. Coenzyme Q10 attenuated DMH-induced precancerous lesions in SD rats. J. Nutr. Sci. Vitaminol. 2010, 56, 139-144. [CrossRef] [PubMed]

17. Karpińska, J.; Mikołuć, B.; Motkowski, R.; Piotrowska-Jastrzebska, J. HPLC method for simultaneous determination of retinol, alpha-tocopherol and coenzyme Q10 in human plasma. J. Pharm. Biomed. Anal. 2006, 42, 232-236. [CrossRef] [PubMed]

18. Littarru, G.P.; Mosca, F.; Fattorini, D.; Bompadre, S. Method to Assay Coenzyme Q10 in Blood Plasma or Blood Serum. U.S. Patent 7303921, 4 December 2007.

19. Botsoglou, N.A. Rapid, sensitive, and specific thiobarbituric acid method for measuring lipid peroxidation in animal tissue, food and feedstuff samples. J. Agric. Food Chem. 1994, 42, 1931-1937. [CrossRef]

20. Paglia, D.; Valentine, W. Studies on the qualitative characterization of erythrocyte glutathione peroxidase. J. Lab. Clin. Med. 1967, 70, 159-169.

21. Marklund, S.; Marklund, G. Involvement of superoxide anion radical in autoxidation of pyrogallol and a convenient assay for superoxide dismutase. Eur. J. Biochem. 1974, 47, 469-474. [CrossRef] [PubMed]

22. Aebi, H. Catalase in vitro. Methods Enzymol. 1984, 105, 121-126. [PubMed]

23. Molyneux, S.L.; Young, J.M.; Florkowski, C.M.; Lever, M.; Georgr, P.M. Coenzyme Q10: Is there a clinical role and a case for measurement? Clin. Biochem. Rev. 2008, 29, 71-82. [PubMed]

24. Lee, B.J.; Huang, Y.C.; Chen, S.J.; Lin, P.T. Coenzyme Q10 supplements reduce oxidative stress and increase activities of antioxidant enzymes in patients with coronary artery disease. Nutrition 2012, 28, 250-255. [CrossRef] [PubMed] 
25. Lee, B.J.; Huang, Y.C.; Chen, S.J.; Lin, P.T. Effects of coenzyme Q10 supplementation on inflammatory markers (high sensitivity C-reactive protein, interleukin-6 and homocysteine) in patients with coronary artery. Nutrition 2012, 28, 767-772. [CrossRef] [PubMed]

26. Lee, B.J.; Tseng, Y.F.; Yen, C.H.; Lin, P.T. Effects of coenzyme Q10 supplementation (300 mg/day) on antioxidation and anti-inflammation in coronary artery disease patients during statins therapy: A randomized, placebo-controlled trial. Nutr. J. 2013, 12, 142. [CrossRef] [PubMed]

27. Yahya, R.S.; Ghanem, O.H.; Foyouh, A.A.; Atwa, M.; Enany, S.A. Role of interleukin-8 and oxidative stress in patients with hepatocellular carcinoma. Clin. Lab. 2013, 59, 969-976. [PubMed]

28. Belghiti, J.; Kianmanesh, R. Surgical treatment of hepatocellular carcinoma. HPB 2005, 7, 42-49. [CrossRef] [PubMed]

29. Makuuchi, M.; Sano, K. The surgical approach to HCC: Our progress and results in Japan. Liver Transpl. 2004, 10, S46-S52. [CrossRef] [PubMed]

30. Poon, R.T.; Fan, S.T.; Lo, C.M.; Ng, I.O.; Liu, C.L.; Lam, C.M.; Wong, J. Improving survival results after resection of hepatocellular carcinoma: A prospective study of 377 patients over 10 years. Ann. Surg. 2001, 234, 63-70. [CrossRef] [PubMed]

31. Liu, H.T.; Huang, Y.C.; Cheng, S.B.; Huang, Y.T.; Lin, P.T. Effects of coenzyme Q10 supplementation on antioxidant capacity and inflammation in hepatocellular carcinoma patients after surgery: A randomized, placebo-controlled trial. Nutr. J. 2016, 15, 85. [CrossRef] [PubMed]

32. Cannistrà, M.; Grande, R.; Ruggiero, M.; Novello, M.; Zullo, A.; Bonaiuto, E.; Vaccarisi, S.; Cavallari, G.; Serra, R.; Nardo, B. Resection of hepatocellular carcinoma in elderly patients and the role of energy balance. Int. J. Surg. 2016, 33, S119-S125. [CrossRef] [PubMed]

33. Muriel, P. Role of free radicals in liver diseases. Hepatol. Int. 2009, 3, 526-536. [CrossRef] [PubMed]

34. Lawrence, T. The nuclear factor NF-кB pathway in inflammation. Cold Spring Harb. Perspect. Biol. 2009, 1, a001651. [CrossRef] [PubMed]

35. Li, S.; Tan, H.Y.; Wang, N.; Zhang, Z.J.; Lao, L.; Wong, C.W.; Feng, Y. The role of oxidative stress and antioxidants in liver diseases. Int. J. Mol. Sci. 2015, 16, 26087-26124. [CrossRef] [PubMed]

(C) 2017 by the authors; licensee MDPI, Basel, Switzerland. This article is an open access article distributed under the terms and conditions of the Creative Commons Attribution (CC-BY) license (http://creativecommons.org/licenses/by/4.0/). 